\title{
A CASE STUDY ON SUSTAINABILITY PRACTICES DURING AN ITALIAN CULINARY SHORT COURSE
}

\author{
Teddy S. Manansala ${ }^{1 *}$, Margarita Isabel L. Marty ${ }^{2}$ \\ ${ }^{1}$ Assistant Professor, De La Salle-College of Saint Benilde, PHILIPPINES, \\ teddy.manansala@benilde.edu.ph \\ ${ }^{2}$ Program Chairperson for Culinary Arts, De La Salle-College of Saint Benilde, PHILIPPINES, \\ margaritaisabel.marty@benilde.edu.ph \\ ${ }^{*}$ Corresponding Author
}

\begin{abstract}
Collaborative partnership between culinary schools based in Italy and the Philippines has been an avenue of extraordinary mastery of culinary art competencies to propel senior students' sustainable growth as future professionals and a necessity in complementing the growing demand of the contemporary hospitality and food industry. With its three-week short course on Italian cuisine and oenology, students and faculty alike experience the flavors and techniques of an authentic Italian gastronomy. This study focused on various kitchen sustainability practices of selected chefs during the Italian culinary short course in line with the United Nations Development Programme (UNDP) Sustainable Development Goal (SDG) No. 12. Specifically, the study sought to describe how the chefs practice sustainability in the kitchen and recommend application of sustainability practices in the context of the Philippine cuisine. A qualitative description design was used wherein researchers applied in-depth direct observations and key informant interviews. Gathered data were transcribed and analyzed using content analysis technique. It is evident that each chef has unique sustainability practices towards maximizing the available ingredients in the kitchen and reduction of food waste. This study revealed three themes for sustainable kitchen practices, namely, sustained culture, local sourcing, and seasonal ingredients. From the perspective of carbon footprint reduction, results show that sustainability practices may be applicable to Philippine-based kitchen practices and management. Future research direction may include impact study among students and perceptions on sustainability practices between chef instructors and the students.
\end{abstract}

Keywords: Italian cuisine, Philippine cuisine, sustainability, sustainable development, carbon footprint, zero food waste

\section{INTRODUCTION}

The global food system is one of the major drivers of global environmental change (Pereira et al., 2019). Experts argue that business-as-usual setup is no longer viable if the world wants a sustainable future. As Pereira et al. (2019) put it in perspective, "what are the means by which we can transform the current food system to become more sustainable, equitable and just?" Global efforts have been done in various capacities. For instance, sustainable intensification of agriculture in the production side has been a significant endeavour (Garnett et al., 2013). Such effort may be anchored in a central principle of 
stewardship where transformations towards sustainability require continuous learning and knowledge generation across knowledge systems about social-ecological systems and their dynamics (Chapin et al., 2010).

By definition, "sustainability is the capacity to create, test and maintain adaptive capability. Development is the process of creating, testing, and maintaining opportunity. The phrase that combines the two, sustainable development, therefore refers to the goal of fostering adaptive capabilities while simultaneously creating opportunities. It is therefore not an oxymoron but a term that describes a logical partnership" (Holling, 2001). The United Nation Development Program (UNDP) Sustainable Development Goals (SDGs), also known as the Global Goals, were adopted by all United Nations Member States in 2015 as a universal call to action to end poverty, protect the planet and ensure that all people enjoy peace and prosperity by 2030 . Whereas, the 17 SDGs are integrated-that is, they recognize that action in one area will affect outcomes in others, and that development must balance social, economic and environmental sustainability. Through the pledge to Leave No One Behind, countries have committed to fast-track progress for those furthest behind first. That is why the SDGs are designed to bring the world to several life-changing 'zeros', including zero poverty, hunger, and food waste (UNDP, 2020).

The food industry, just like other industries is driven by the forces of supply and demand. Hence, it is important to include this factor when addressing food sustainability (Hall and Gossling, 2013). Whereas, the goal of food sustainability can be narrowed down to two objectives: first, to manage food resources such that it can supply the needs of the population while not endangering the resources available for the future generation, second, to minimize or mitigate the adverse impact of food production and distribution on the environment (Baldwin, 2015). Meanwhile, the concept of culinary sustainability may include aspects such as green kitchen, sustainable cuisine, food value system, sustainable product and process innovation, waste management, culinary trends, renewable energy, and local food system (Khan, 2014).

This paper focuses on sustainability concept towards zero food waste in the context of a chef's kitchen in an Italian culinary institute. It also dissects two countries' culture and tradition in the same context of sustainability in the kitchen. For Montanari (2006, p. 7), "what we call culture takes place where tradition and innovation intersect."

Tradition and innovation intersect through cooking as chefs may be regarded as innovators and agents of change in the food system. Considering chefs potential, the following three-level framework of 'deliciousness' as described by Evans et al. (2015) at the Nordic Food Lab is useful to consider: (1) the perceptual, or sensory, level; (2) the functional level, referring to nutrition and safety; and (3) the creation level, where the ideas, philosophies and ethics underpinning food are located. The pursuit of what Evans et al. (2015, p. 3) term "irresistible" deliciousness - achieved through the synergy of excellence at all three levels - pushes chefs to "discover and rediscover unique sources of deliciousness," often by engaging with neglected and underutilized food materials and by exploring diverse culinary knowledge from around the world. This motivation, and particularly the third level of deliciousness where ideas and ethics are situated, holds potential for productive engagement with food system transformation efforts (Pereira et al., 2019).

Considerably, chefs and cooks may help showcase diversity by creating a more sustainable and equitable food system through incorporation of the underutilized and traditional species in their cooking (Bioversity International, 2017; IPES-Food, 2016). Pereira et al. (2010) argues the false dichotomy in which a contentious divide between the idea of a 'cook' and a 'chef', with the former being generally less highly regarded than the latter, who is understood to operate in the realm of 'gastronomy' or "the science of the kitchen and the art of eating well" (Artusi, 2003). As highlighted by Haider and van Ouderhouven (2018, p. 1), who propose that food "as a daily art" in agricultural communities "incorporates ideas of health, spirituality, community, technology, and trade, and connects the most marginalized with the most powerful." Here, the power of food as a connector is recognized where those that wield the knowledge over how to make it delicious (ranging from a grandmother-as-cook to a Michelin-starred chef) have a transformative power. In order to break the stereotypes so prominent in gastronomy, in this paper, cooks and chefs interchangeably are used interchangeably as what really matters in the argument are their skills and knowledge about food. Chefs' innovative use of the diversity of tastes, sights and colours around them, may bring back a sense of place and heritage to the food they prepare in their kitchens (Pereira et al., 2019).

This paper explores how sustainability practices may be applicable from one country to another as in the case of a culinary institute in Italy and another culinary school in the Philippines. As viewed by Montanari (2006), innovation and tradition arise from culture and that the two countries in the paper may share similarities such as in the use of local ingredients, family table, regional development, and peasant origins. 
Historically, Italian and Philippine food cultures are reliant on local available ingredients. For the Italians, the abundance of wheat and olives made their food culture developed pasta as their staple and the use of olive oil as a distinct ingredient of Italian cuisine. Meanwhile, Philippine agriculture is dominated by rice, thus has become the local staple and the abundance of coconuts throughout the archipelago have made all coconut derived ingredients widely used in various recipes of the country. Despite the influx of foreign influence for both Italian and Philippine food cultures, the core of both have retained their identities and have evolved in their own distinct way.

From the lens of both Italian and Philippine cultures, family has played a central role. As much as possible, meals are ideally taken as a family, and both share the concept of an extended family. This greatly influenced the development of their cuisines both on the level of regular day to day fare as well as those meant for feasts or special occasions.

The Italian food culture varies for every region driven by factors such as availability of ingredient and they type of influences they have received. For instance, the southern region is known for its use of olive oil, since most of the olive oil growers belong to that region, while the northern part tends to use more butter due to their proximity to the dairy farms. The Philippines being made of more than 7,000 islands, the same set of factors, would drive the development of a diverse regional food culture. For instance, the Bicol region in the southern part of the island of Luzon uses coconut milk and the local chilies ( sill), this is best shown in their local delicacy called laing-which is basically shredded taro leaves with shredded meat cooked in coconut milk and chilies (Barretto, et al., 2008).

In both Italian and Philippine food cultures, their origins can be traced to the common folk, this is certainly consistent with the family-centered character of both cuisines, as the family table of the common folk has really served as the incubator of both cuisines. The taste and the circumstance of the common family were the drivers of the local recipes. The cuisines for both food cultures were representative of the common taste. Pasta for the Italians and rice for the Filipinos were staples of the common folk.

\section{METHODOLOGY}

This study adapted a qualitative description (QD) research design. Whereas, QD is a label used in qualitative research for studies which are descriptive in nature (Polit \& Beck, 2009, 2014). This method has been cited identified as important and appropriate for research questions focused on discovering the who, what, and where of events or experiences and gaining insights from informants regarding a poorly understood phenomenon. Further, QD is also the label of choice when a straight description of a phenomenon is desired or information is sought to develop and refine questionnaires or interventions (Neergaard et al., 2009; Sullivan-Bolyai et al., 2005). QD is the most applicable for this study as the details of chefs' kitchen practices and management were documented and analyzed.

\subsection{Data Requirements}

\subsubsection{Locale of the Study}

The culinary school is located in the small hilly town south of the city of Asti in Italy. The town plays host to small family owned and operated restaurants, local food shops and a Saturday farmers' market. It is surrounded by vineyards with years of wine making tradition. Located in the region of northwest region of Piedmont the location makes it ideal for the study of Italian culinary courses.

The serene environment of the campus makes it conducive for an aspiring chef to find the passion in Italian cuisine. The impressive medieval castle is home to the school's restaurant, kitchens, wine and olive oil cellar. Students are taught on Italian culinary history, traditional Italian dishes from the different regions of Italy, wine appreciation, and wine and food pairing.

\subsubsection{Participants and Sampling}

Purposive sampling was used to select chefs that were included in the study. Criteria for participants' selection include: (a) exhibited sustainability practices during the class kitchen demonstration, (b) at least 10 years of professional experience as a cook/chef, and (c) willingness to be part of the study. Participants were given pseudo names for confidentiality.

\subsubsection{Instrument}

A semi-structured interview questionnaire with open-ended questions was administered on chosen participants to further elicit insights on their exhibited sustainable practices. 


\subsubsection{Secondary Data}

Researchers conducted further gathering on secondary data relative to the background and profile of the participants from their restaurant affiliations and websites.

\subsection{Data Gathering}

Permission to conduct data gathering was obtained from the educational director and head office manager during the duration of the three-week short course on Italian cuisine and oenology. Researchers documented all the kitchen demonstrations by video- and photo-documentation with prior permission. In-depth direct observations were done for every kitchen demonstration and able to identify who among the chefs exhibited notable sustainability practices. Key informant interviews were conducted right after the kitchen demonstration by the participating chefs where the semi-structure interview questionnaire was administered. School's official interpreter translated the participants responses from Italian to English language.

Direct in-depth observations were likewise conducted in the entire three-week course as to how the school classes and the kitchen operates, for instance, the flow of food.

\subsection{Data Analysis}

As primary data were obtained from in-depth direct observations and key information interviews, participants responses were transcribed and subjected to thematic analysis and determine themes and patterns.

\section{RESULTS}

\subsection{Kitchen Laboratory Chefs}

\subsubsection{Traditional Chef}

With more than 40 years of kitchen experience, this "traditional chef" has cooking inscribed in her DNA: As an adolescent, she kept a notebook in which she meticulously wrote down Piedmont's best traditional recipes for desserts and other dishes. Her genuine passion for the profession was immediately unleashed, stimulating her creativity and desire to develop the image of the restaurant she worked in. A brilliant career that began at just 18 years of age, with distinctions and awards on a national and international level. Legitimately considered one of the best chefs in Piedmont as well as in Italy, this "traditional chef" was soon asked to give classes in haute cuisine, for example, at the prestigious culinary institute in Asti. She has frequently spent time abroad in Canada, the United States, Japan, Germany, and Switzerland, where she has offered her dishes in the best European and international restaurants and held training demonstrations at the highest levels (ITO, 2020).

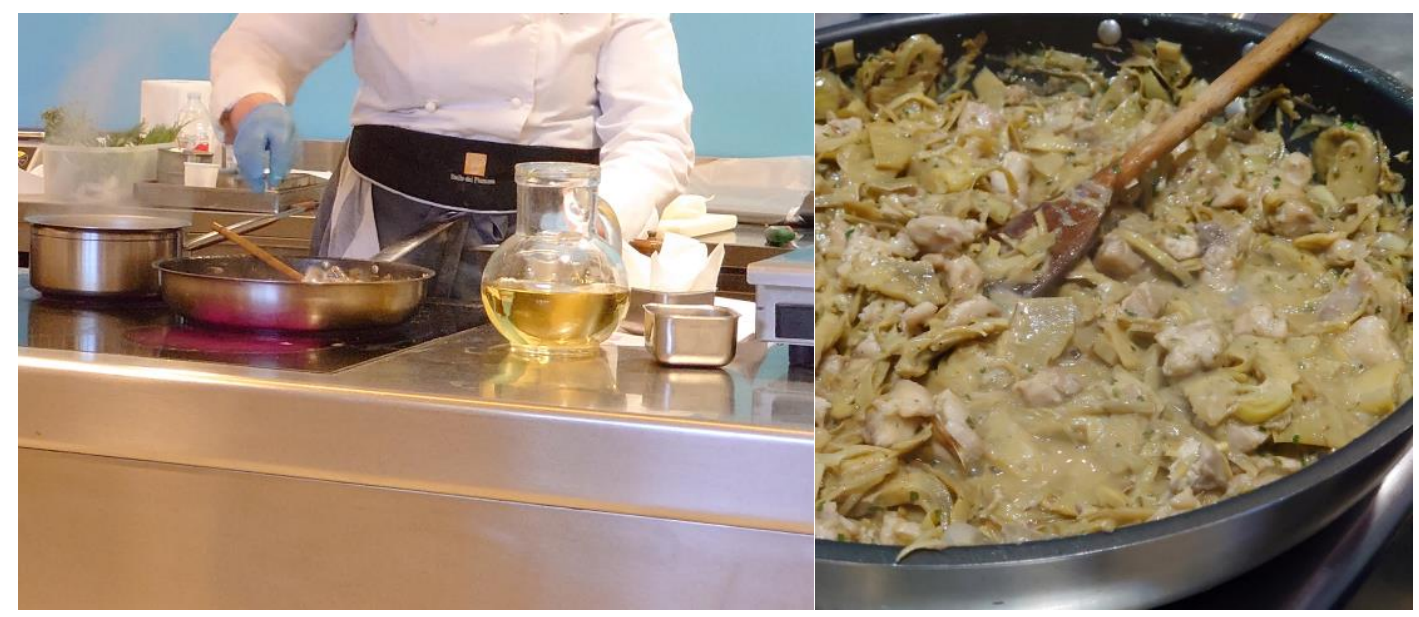

Figure 1. Cooking demonstration by the "traditional chef"

In Figure 1, a "traditional chef" conducts a cooking demonstration where she substituted an ingredient with a seasonal one. For her, "In my cooking, I pay a great deal of attention to selecting the ingredients, always respecting when they are in season. I love studying both the well- and lesser-known traditional recipes, rediscovering forgotten dishes, which I experiment with, modify and improve. It's an ongoing effort of historical and practical exploration." 


\subsubsection{Modern Chef}

This "modern chef" has almost thirty years of experience where he had the opportunity to get to know and learn different disciplines from the world of gastronomy, such as traditional cuisine, bread-making, pastry. As in the sector foodservice as in many others, the foundations are fundamental, but in the nature of the human being there has always been the desire to evolve, and to know. Whereas, he has immersed himself to study and experience principles behind the field of gastronomy.

Not only because they are part of the world of gastronomy, but because the ingredients and the physical and chemical reactions are the same in every sector, for instance, Maillard's reaction that one sees as a process when cooking a pan of Spain, takes place in the cooking of a rib or on a form of bread.

The study and knowledge of this matter, allows this "modern chef" to deal not only with cooking, traditional pastry and bread-making, but also with being able to work in the world of "molecular" gastronomy, with being able to create recipes from the three environments, with techniques and last generation.

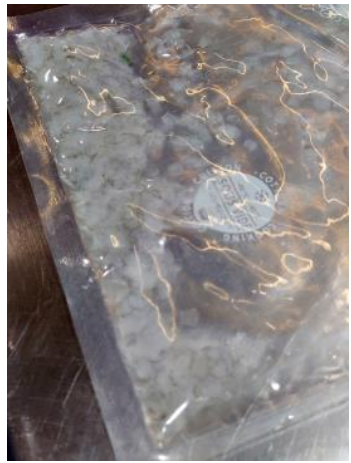

a

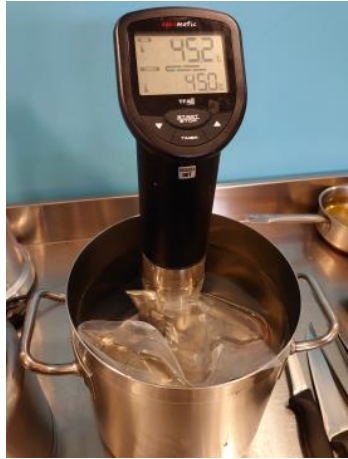

b

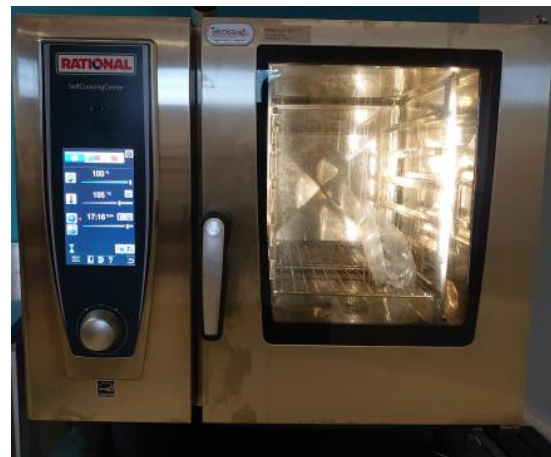

C

Figure 2. "Modern chef" processes the fish scales through (a) vacuum-sealing, (b) sous vide cooking method, and then subjected to (c) oven drying

As shown in Figure 2, fish scales have undergone three steps of processing prior to its use as garnish to main course for added texture and nutritional value. As this "modern chef" articulates, "This knowledge allows me to be able to operate in these sectors. More and more the chef figure must be seen as a multifaceted and competent figure, with this I do not mean that you have to be a "wholesaler" rather you have to be wary of such people. Behind me is an evolution that led me to a more traditional start that saw me protagonist in important international kitchens in Italy and abroad, both as a collaborator and as an owner to become a consolidated and recognized consultant, an application chef as they say, or a multifaceted figure capable of both developing new products and recipes, and structuring a restaurant from scratch, designing processes from production to administration."

\subsection{From Kitchen Laboratory to Kitchen Restaurant}

The Italian culinary institute has its way of ingredients procurement to assure high quality raw materials in creating delectable and palate-stimulating dishes. It cultivates its own herb garden as the backyard and accessible whenever needed for its cuisine and pastry classes. The herbs organic nature and freshness contribute in the wholesomeness of the final product. Meanwhile, fruits and vegetables are purchased for local farms and/or vendors in the local farmer's market. Meats are sourced from local producers to ensure premium quality of choice.

Through the years under the instruction of its resident chef-instructor, the recipes have been refined to exact measurements. When recipes are executed, the ingredients are scaled to exact portions to avoid waste. Students are expected to do measurements of ingredients for the mise-en-place before demonstration and hands-on classes. All of the excess ingredients are then returned to the main kitchen to be used either by other classes or in the production of student meals. Recipes for lessons are also carefully planned so that the ingredients required are in season and locally available.

For gelato classes, mise-en-place is done during the class. Students have access to all the ingredients, which they scale carefully following the standardized recipes. Similarly, excess ingredients are sealed then properly stored or returned to the main kitchen for use in other classes or meals.

During bread and pastry classes, large quantities of bread and pastry products are produced. After students 
partake and done with organoleptic evaluation, excess products are preserved in the blast freezer and then reheated prior to serving as needed. Pastries and gelato are reserved and served to the students during meals and breaks.

The institute's main kitchen is managed by a communard chef. Sign-up sheets are posted daily to ensure that he prepares the exact number of meals. The communard chef prepares vegetarian dinner options, including fresh salads and strongly encourages the students to take this healthy and environment-friendly meals option. Just like the resident chef-instructor, a communard chef also plans his recipes to ensure that the ingredients required are in season so that they may be easily out-sourced locally. Close coordination between a communard chef and the resident chef-instructor is observed to ensure that perishable ingredients do not go to waste.

The institute also practice the waste segregation system in both kitchen laboratory classroom, the main kitchen, and the dining. Waste-segregated receptacles are placed throughout kitchen laboratory classroom and students are taught on the proper use. Resident chef-instructor also inspects the receptacles at the end the hands-on classes and deductions are given for non-compliance. Meanwhile, vegetable scraps and coffee ground are used for compost to fertilize the institute's herb garden.

\subsection{Environmental Implications}

Thematic analysis of obtained data streamlined into three themes result namely, sustained culture, local sourcing, and seasonal ingredients.

\subsubsection{Sustained Culture}

Culture and sustainable development are intertwined and may become an instrument in achieving sustainability goals. These goals are essentially dependent on human accounts, actions, and behavior, which are, in turn, culturally embedded (Soini and Dessein, 2016). Cultural sustainability is approached through storylines of cultural heritage, cultural vitality, economic viability, cultural diversity, locality, ecocultural resilience, and eco-cultural civilization (Soini and Birkeland, 2014). Moreover, the culture theory and its role in development, in society, and in nature may also focus on the value of culture and the modes of governance and policies (Soini and Dessein, 2016). At micro level, as in the case of the Italian culinary school, policies and kitchen protocols exemplify sustainability practices anchored on culture and distinct gastronomic experiences. State policies such as waste segregation and recycling are strictly enforced. Meanwhile, food ingredients selection and efficient utilization of vegetables, fruits, and pasta products have low carbon footprints (Fritsche and Eberle, 2009).

\subsubsection{Local Sourcing}

Buying local ingredients is one key aspect of culinary sustainability. It has domino effect on the production cycle and the environment. As every final product depends on the quality of the raw materials used in the same manner as in cooking good food is all about freshest, finest, and readily available ingredients (Benjamin and Virkler, 2016). A relatively short distance food travels from farm to fork denotes low carbon footprint (Fritsche and Eberle, 2009).

In terms of carbon footprint of transport of food, it has been noted that the freight transport of food constitutes a share of around three percent of greenhouse gas emissions arising from the 'food' demand category. This means that in view of the overall demand category-from agricultural production through the processing, distribution, and trade to storage, preparation and household consumption-measures which aim to increase the efficiency of household devices can achieve significantly greater effects in terms of the carbon footprint than measures which aim to reduce freight transport (Wiegmann et al., 2005). As in the case of the Italian culinary school under study, all of the storage and production equipment are properly operated and maintained.

\subsubsection{Seasonal Ingredients}

Another evident sustainability practice among the chefs in the institute is the use of locally available seasonal ingredient such as fruits and vegetables. In study of Stoessel et al. (2012), results showed that the largest reduction of environmental impacts can be achieved by consuming seasonal fruits and vegetables, followed by reduction of transport by airplane. Sourcing fruits and vegetables locally is only a good strategy to reduce the carbon footprint if no greenhouse heating with fossil fuels is involved.

\section{CONCLUSIONS}


Taking a close look at both Italian and Philippine cultures, 'going back to the basics' would actually translate into practices that are friendly to food sustainability. The reliance of both to local ingredients would mean that the transport leg of the food cycle would be shorter and thus friendlier to the environment. What transpired in the three-week short course on Italian Cuisine and Oenology, observations on kitchen practices in the institute and among the chefs, and key-informant interviews revealed three themes for sustainable kitchen practices, namely, sustained culture, local sourcing, and seasonal ingredients. Italy and Philippines having similarities in various cultural aspects, kitchen practices are therefore relevant in the context of the Philippine kitchen. What bind both cultures are the culinary sustainability practices that may help contribute in the realization of the UNDP SDGs. Future research direction may include impact study among students and perceptions on sustainability practices between chef instructors and the students.

\section{REFERENCE LIST}

Artusi, P. (2003). Science in the Kitchen and the Art of Eating Well. University of Toronto Press.

Baldwin, C.J. (2015). The 10 Principles of Food Industry Sustainability. John Wiley \& Sons, Inc.

Barretto, G.R., Calalang, C., Fores, M., Segismundo, M., Sincioco, J., and Tayag, C. (2008). Kulinarya: A Guide to Philippine Cuisine. Anvil, Philippines.

Benjamin, D., \& Virkler, L. (2016). Farm to table: The essential guide to sustainable food systems for students, professionals, and consumers. White River Junction, Vermont: Chelsea Green Publishing.

Bioversity International (2017). Mainstreaming Agrobiodiversity in Sustainable Food Systems: Scientific Foundations for an Agrobiodiversity Index. Retrieved from https://www.bioversityinternational.org/fileadmin/user_upload/online_library/Mainstreaming_Agrobiodiv ersity/Mainstreaming_Agrobiodiversity_Sustainable_Food_Systems_WEB.pdf.

Chapin, F. S. S., Carpenter, S. R. S. R., Kofinas, G. P. G. P., Folke, C., Abel, N., Clark, W. C. W. C., ... Swanson, F. J. (2010). Ecosystem stewardship: Sustainability strategies for a rapidly changing planet. Trends in Ecology \& Evolution, vol. 25 (4).

Damiano, D. (2020). Chef Davide Damiano: Chef Consulente. Retrieved from https://en.chefdavidedamiano.com/

Evans, J., Flore, R., Astrup Pedersen, J., \& Bom Frøst, M. (2015). Place-based taste: Geography as a starting point for deliciousness. Flavour, vol. 4 (1).

Fritsche, U.R. and Eberle, U. (2009). Working Paper: Greenhouse-Gas Emissions from the Production and Processing of Food. Retrieved from http://iinas.org/tl_files/iinas/downloads/food/2009_GHG_food.pdf

Garnett, T., Appleby, M. C., Balmford, A., Bateman, I. J., Benton, T. G., Bloomer, P., ... Godfray, H. C. J. (2013). Sustainable intensification in agriculture: Premises and policies. Science, 341(6141).

Hall, C.M. and Gossling, S. [eds.]. (2013). Sustainable Culinary Systems: Local foods, innovation, tourism and hospitality. Routledge, New York.

Haider, L. J., \& van Oudenhoven, F. J. W. (2018). Food as a daily art: Ideas for its use as a method in development practice. Ecology and Society, vol. 23.

Holling, C.S. (2001). Understanding the complexity of economic, ecological, and social systems. Ecosystems, vol. 4.

IPES-Food (2016). From Uniformity to Diversity: A Paradigm Shift from Industrial Agriculture to Diversified Agroecological Systems. Retrieved from http://www.ipesfood.org/images/Reports/UniformityToDiversity_FullReport.pdf.

Italian Tourist Office [ITO]. (2020). A Guide Chef of Piedmont. Retrieved from http://www.italiantouristoffice.se/sv/docs/35.pdf

Khan, M.A. (2014). Advances is Hospitality and Tourism Series: Managing Sustainability in the Hospitality and Tourism Industry-Paradigms and Directions for the Future. CRC Press.

Montanari, M. (2006). Food is Culture. Columbia University Press. 
Neergaard, M.A., Olesen, F., Andersen, R.S., Sondergaard, J. (2009). Qualitative description - the poor cousin of health research? BMC Medical Research Methodology vol. 9 (52). PubMed: 19607668

Pereira, L. M., Calderon-Contreras, R., Norstrom, A.V., Espinosa, D., Willis, J., Laram L.G., ... Amaya, O.P. (2019). Chefs as change-makers from the kitchen: indigenous knowledge and traditional food as sustainability innovations. Global Sustainability, vol. 2 (e16). https://doi.org/10.1017/S2059479819000139

Polit, D.F., Beck, C.T. (2009). International differences in nursing research, 2005-2006. Journal of Nursing Scholarship, vol. 41(1). PubMed: 19335677

Polit, D.F, Beck, C.T. (2014). Essentials of Nursing Research: Appraising Evidence for Nursing Practice. 8. Philadelphia, PA: Wolters Kluwer Health; Lippincott Willians \& Wilkins. Supplement for Chapter 14: Qualitative Descriptive Studies. Retrieved from http://downloads.Iww.com/wolterskluwer_vitalstream_com/samplecontent/9781451176797_Polit/samples/CS_Chapter_14.pdf

Soini, K. and Dessein, J. (2016). Culture-Sustainability Relation: Towards a Conceptual Framework. Sustainability, vol. 8.

Soini, K. and Birkeland, I. (2014). Exploring the scientific discourse on cultural sustainability. Geoforum, vol. 51.

Stoessel ,F., Juraske, R., Pfister, S., and Hellweg, S. (2012). Life cycle inventory and carbon and water food print of fruits and vegetables: application to a Swiss retailer. Environ Sci Technol, vol. 46 (6).

Sullivan-Bolyai, S., Bova, C., Harper, D. (2005). Developing and refining interventions in persons with health disparities: the use of qualitative description. Nursing Outlook, vol. 53(3). PubMed: 15988449

United Nations Development Programme [UNDP]. (2020). Sustainable Development Goals. Retrieved from https://www.undp.org/content/undp/en/home/sustainable-development-goals.html

Wiegmann, K., Eberle, U., Fritsche, U. R., and Hünecke, K.. (2005). Umweltauswirkungen von Ernährung Stoffstromanalysen und Szenarien; Ernährungswende-Diskussionspapier Nr. 7 des Öko-Instituts“; Darmstadt/Hamburg. Retrieved from www.ernaehrungswende.de/pdf/DP7_Szenarien_2005_final.pdf 